Vebi Hanifatun Saleha, Karjuni Dt. Ma'ani I Implementasi Kebijakan Program Bedah Kemiskinan Rakyat Sejahtera (BEKERJA) dalam Menjamin Ketahanan Pangan Masyarakat di Nagari Lubuk Layang Kabupaten Pasaman

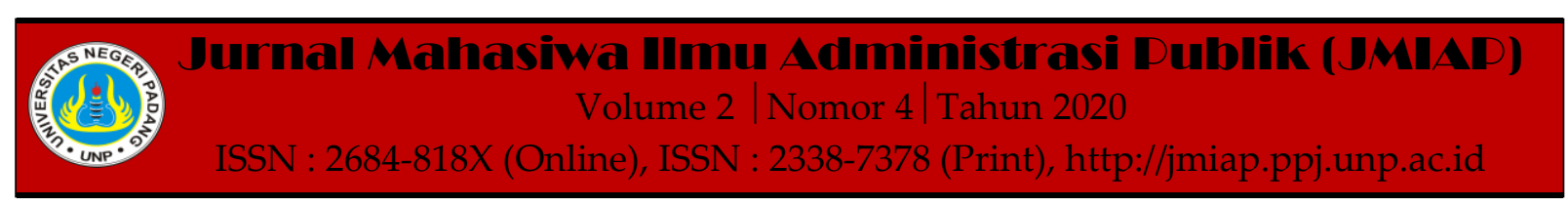

\title{
IMPLEMENTASI KEBIJAKAN PROGRAM BEDAH KEMISKINAN RAKYAT SEJAHTERA (BEKERJA) DALAM MENJAMIN KETAHANAN PANGAN MASYARAKAT DI NAGARI LUBUK LAYANG KABUPATEN PASAMAN
}

\author{
Vebi Hanifatun Saleha ${ }^{1(a)}$, Karjuni Dt. Ma'ani ${ }^{2(b)}$ \\ ${ }^{1}$ Jurusan Ilmu Administrasi Negara, Universitas Negeri Padang \\ ${ }^{2}$ Jurusan Ilmu Administrasi Negara, Universitas Negeri Padang \\ a)febyhanifatun@gmail.com, ${ }^{b)}$ dt.maanikarjuni63@fis.unp.ac.id
}

\begin{abstract}
This research is based on the inability of the family to meet food needs. The research objective is to explain the implementation, factors and solutions to overcome the obstacles of the Work Program in Ensuring Food Security of the Nagari Lubuk Layang Pasaman Community. The method in this research is descriptive qualitative. The research was conducted in Nagari Lubuk Layang, Pasaman Regency. Research informants were determined by purposive sampling. Research data obtained from observation, interviews and documentation. The data validity test was done by triangulating the source, then the data was analyzed by reducing, displaying, and drawing conclusions from the research. The research results show that the implementation of the Prosperous People Poverty (Work) Program policy in ensuring community food security has not been carried out properly, because the community still does not know about the Work program in ensuring community food security in Nagari Lubuk Layang, Pasaman Regency. The factors that influence the implementation of the Work Program in ensuring food security for the people in Nagari Lubuk Layang, Pasaman Regency, consist of three factors, namely land ownership, education, income. Furthermore, efforts to overcome these obstacles are to increase public awareness and carry out direct supervision.
\end{abstract}

Keywords : Implementation of Policies, Surgery Poverty Prosperous People

Corresponding author. Email.febyhanifatun@gmail.com

How to cite this article. Saleha, V. Hanifatun \& Ma'ani, K.(2020). Implementasi Kebijakan Program Bedah Kemiskinan Rakyat Sejahtera (BEKERJA) dalam Menjamin Ketahanan Pangan Masyarakat di Nagari Lubuk Layang Kabupaten Pasaman. Jurnal Mahasiwa Ilmu Administrasi Publik (JMIAP) Jurusan Ilmu Administrasi Negara Fakultas Ilmu Sosial Universitas Negeri Padang, Volume 2 (4), Hal. 70-77.

http://jmiap.ppj.unp.ac.id

ISSN : 2684-818X (Online), ISSN : 2338-7378 (Print)

Copyright@2020. Published by Labor Jurusan Ilmu Administrasi Negara FIS UNP, Padang 
Vebi Hanifatun Saleha, Karjuni Dt. Ma'anil Implementasi Kebijakan Program Bedah Kemiskinan Rakyat Sejahtera (BEKERJA) dalam Menjamin Ketahanan Pangan Masyarakat di Nagari Lubuk Layang Kabupaten Pasaman

\section{PENDAHULUAN}

Ketidakmampuan keluarga dalam memenuhi kebutuhan pangan yang merupakan kebutuhan paling dasar menjadi kendala dalam upaya keluar dari kemiskinan. Dalam konteks penanggulangan kemiskinan dan ketahanan pangan adalah faktor kunci dalam penanggulangan masyarakat miskin sehingga penguatan ketahanan pangan memberikandampak yang signifikan. Intinya di Indonesia pembangunan masyarakat yang terampil sangat penting dilakukan melalui ketersediaan pangan yang memadaidan terjangkau bagi daya beli masyarakat. (Rosyadi \& Purnomo, 2012).

Kebutuhan pangan ialah hak yangharus dihormati oleh seluruh warga negara. Pangan merupakan kebutuhan dasar manusia untuk bertahan hidup. Di Indonesia sudah diatur dalam Undang-Undang Nomor 18 tahun 2012 tentang Pangan. Pasal 1 ayat 4 yang dimaksud dengan Ketahanan pangan adalah kondisi penyediaan pangan bagi individudiwujudkan dengan ketersediaan pangan yang mencukupi, baik secara kuantitas, kualitas, aman, beragam, bergizi, merata dan terjangkau serta tidak berlawanan dengan agama, kepercayaan, budaya masyarakat, sehat, aktif, produktif untuk waktu yang lama.

Hal ini menegaskan pangan adalah kebutuhan dasar manusia. Tingkat ketahanan pangan di Indonesia dinilai masih rendah, kurang beragam, tidak merata dan tidak terjangkau. Pemerintah Kabupaten Pasaman saat ini telah bekerja keras bersama petani menjaga ketersediaan pangan yang berkualitas. Pemenuhan kebutuhan pangan menjadi kewajiban pemerintah agar kebutuhan setiap warganya terpenuhi. Terkait dengan hal tersebut Pemerintah Kabupaten Pasaman berupaya untuk mewujudkan ketahanan pangan di daerah ini dengan melaksanakan berbagai upaya, yaitu melaksanakan Program BEKERJA. Program ini bertujuan untukmemberdayakan masyarakat tidak mampu untuk meningkatkan penghasilan dan kesejahteraannya melalui pertanian terintegritas. Namun dalam pelaksanaannya Program tersebut belum berdampak signifikan pada Rumah Tangga Miskin pertanian (RTMP). Misalnya, belum terpenuhinya nutrisi yang seimbang, pembagian bantuan yang tidak merata, tidak tepatnya sasaran, karena masih ada RTMP yang tidak mendapatkan bantuan tersebut. Padahal program ini dapat meningkatkan ketahanan pangan bagi Rumah Tangga Miskin Pertanian (RTMP) dan penanggulangan kemiskinan.

Dalam rangka meningkatkan ketahanan pangan maka dari itu telah ditetapkanPeraturan Menteri Pertanian Nomor 27/PERMENTAN/RC.120/5/2018 tentang Perubahan Atas Peraturan Menteri Pertanian Nomor 20/ PERMENTAN/ RC.120/ 5/ 2018 tentang Pedoman Program Bedah Kemiskinan Rakyat Sejahtera Berbasis Pertanian Tahun Anggaran 2018. Dalam Peraturan Menteri ini dimaksudkan sebagai pedoman dalam melaksanakan Program Bekerja dengan tujuan memberdayakan/ meningkatkan kapasitas masyarakat miskin dalam melaksanakan usaha pertanian untuk menunjang pendapatan, kesejahteraan melalui pertanian terintegritas.

Program Bekerja menjadi gebrekan baru pemerintah dalam memberikan bantuan kepada masyarakat miskin. Bantuan program Bekerja diarahkan pada komoditas yang mempunyai keunggulan komparatif di setiap daerah yang menghasilkan nilai ekonomi tinggi dan terfokus pada kawasan penduduk miskin yang dikelompokkan menjadi 3 kelompok. Adapun jenis bantuan yang diberikan melalui program Bedah Kemiskinan Rakyat Sejahtera (Bekerja) ini yaitu:

1) Jenis bantuan jangka pendek dan menengah melalui dua jenis bantuan yaitu: a) Sayur-sayuran yaitu, kangkung, bayam, sawi, kacang panjang, pare, timun, buncis, dan jagung manis satu bungkus beserta polybag; dan b) Bibit ayam petelur 
berumur dua bulan 50 ekor beserta kandang yang dimana biaya kandang 500 ribu dan pakan $200 \mathrm{~kg}$.

2) Jenis bantuan jangka panjangnya yaitu tanaman perkebunan, yaitu coklat 4 batang, durian 1 batang.

Melalui program kerja ini diharapkan rumah tangga miskin dapat memperoleh penghasilan sekitar Rp 2 hingga 2,3 juta/ bulan atau Rp 550.000/ kapita/ bulan. Jumlah pendapatan tersebut jauh dari garis kemiskinan, yaitu sekitar Rp 370.000/ jiwa/ bulan.

Program Bekerja tidak hanya sekedar memberikan bantuan, namun disertai dengan pendampingan dan edukasi kepada RTM guna meningkatkan usaha mandiri. Aksi ini sebagai wujud nyata Kementrian Pertanian dalam upaya meningkatkan kesejahteraan masyarakat (petani) dan akselerasi penurunan angka kemiskinan.

Dalam pelaksanaan program Bedah Kemiskinan Rakyat Sejahtera (Bekerja) di Nagari Lubuk Layang Kabupaten Pasaman, masih terdapat beberapa masalah dalam pelaksanaannya salah satunya adalah tidak adanya pelatihan/ pengawasan yang diberikan kepada masyarakat cara membudidayakan bantuan yang telah di berikan. Sehingga ada sebagian dari masyarakat menjual kembali bantuan yang diberikan dikarenakan mereka tidak paham cara membudidayakan bantuan tersebut.

Selain itu, faktor penghambat terlaksananya Program Bedah Kemiskinan Rakyat Sejahtera (Bekerja) adalah masih banyaknya masyarakat yang belum mengetahui karena kurangnya sosialisasi dari pemerintah. Terlihat bahwa partisipasi masyarakat dalam mensukseskan programBedah Kemiskinan Rakyat Sejahtera (Bekerja) masih rendah, sehingga nampaknya kesadaran dan partisipasi masyarakat dapat menghambat pelaksanaan Program Bedah Kemiskinan Rakyat Sejahtera (Bekerja). Oleh karena itu, sosialisasi harus selalu dilakukan agar tercipta partisipasi masyarakat dalam program tersebut.

\section{TINJAUAN PUSTAKA}

\section{Konsep Kebijakan Publik}

Wahab (Wahab.S, 2013, p. 133) mengemukakan bahwa Implementasi dianggap sebagai sistem pengoperasionalisasian atau pelaksanaan aktifitas yang sudah diatur dalam UndangUndang dan jadi persetujuan bersama diantara berbagai pihak yang terkait, organisasi (Publik maupun privat) metode secara sinergis yang diarahkan untuk melaksanakan kebijakan kearah yang dikehendaki. Wahab berpendapat dengan cara seperti ini bertujuan agar perilaku dan pikiran segenap pihak yang terkaitdapat ditanggulangi serta terjaga pada koridornya.

Menurut Anderson dalam (Arenawati, 2014) kebijakan ialah perbuatan yang memiliki tujuan yang dilakukan seorang untuk menyelesaikan satu masalah, yang bertujuan untuk memenuhi kebutuhan dan kepentingan masyarakat.

William N. Dun (Pasolog, 2007, p. 39) juga memaknai kebijakan publik yaitu suatu rangkaian pilihan dan saling berhubungan, dilakukan instansi atau stakeholder yang berkaitan dengan tugas pemerintahan, misalnya kesejahteraan masyarakat, baik wilayah perkotaan dan perdesaan. Dan oleh karena itu, kebijakan publik dapat dijelaskan sebagai rangkaian perbuatan yang dilakukan atau tidak oleh pemerintah, baik oleh satu orang maupun sekelompok orang untuk mencapai tujuan tertentu yang berorientasi pada kepentingan masyarakat.

Menurut Carl Friedrich (Dwiyanto, 2009, p. 18) kebijakan merupakan salah satu kegiatanyang dilakukan oleh individu, kelompok atau pemerintah di suatu wilayah berkaitan dengan adanya kendala ketika mencari kesempatan untuk mencapai sasaran.

Kebijakan publik merupakan bidang di mana adanya pihak yang bergantung dalam menyelesaikan masalah secara rasional dan diterima oleh kelompok kepentingan, serta juga dapat dikembangkan sebagai senjata untuk mendorong perubahan sektor publik sehingga gerakan reformasi berjalan lebih 
Vebi Hanifatun Saleha, Karjuni Dt. Ma'anil Implementasi Kebijakan Program Bedah Kemiskinan Rakyat Sejahtera (BEKERJA) dalam Menjamin Ketahanan Pangan Masyarakat di Nagari Lubuk Layang Kabupaten Pasaman

cepat dari yang diupayakan. (Dwiyanto, 2009, p. 55)

\section{Implementasi Kebijakan}

Implementasi kebijakan publik ialah suatu kegiatan dalam metode aturan yang menentukan suatu kebijakan bersinggungan dengan kebutuhan umum dan diakui oleh orang banyak. Dengan demikian dapat mengendalikan bahwa pada perencanaan dan perumusan kebijakan dimungkinkan untuk melakukan yang terbaik, tetapi jika tahap optimalisasi tidak diperhitungkan, maka tentunya suatu produk kebijakan tidak jelas. Dan sudah dipastikan bahwa tahap penilaian perumusan dan pelaksanaan seringkali belum konsisten, sehingga pelaksanaan kebijakan tidak konsisten. Tidak seperti yang diinginkan bahkan menjadi penghalang pembuat kebijakan. (Aneta, 2012).

Menurut Dunn (2003:132) dalam (. et al., 2016) Implementasi kebijakan adalah pelaksana kontrol atas tindakan kebijakan selama periode waktu tertentu. Menurut Widodo (. et al., 2016)menyatakan bahwa implementasi kebijakan adalah proses penerapan aturan yang belum jelaskedalam realita nyata. Jadi implementasi kebijakan ialah bentuk dari kebijakan yang sudah dilakukan dalam rentang waktu yang di tentukan.

Daniel Mazmanian dan Paul Sabatier (Leo, 2008, p. 139) mendefenisikan implementasi kebijakan sebuah ketetapanawal, berupa undang-undang, tetapi bisa juga dalam bentuk keputusan eksekutif danyudisial yang bermakna. Sebagai aturan, ketentuan mengidentifikasi masalah yang akan dipecahkandalam menyusun proses implementasi dengan tujuan yang diinginkan dengan cara berbeda.

Indiahono (Dwiyanto, 2009, p. 143) menjelaskan bahwa Implementasi kebijakan mengacu pada kegiatan pelaksana kebijakan di dunia nyata, yang dilakukan oleh badan pemerintah maupunpihak yang telah ditentukan yang merupakan langkah penting dari kebijakan tersebut. Langkah ini menyatakan apakah pemerintah telah menerapkan kebijakan dengan benar dan berhasil sebagaimana dimaksud.

Jones (1996) (Leo, 2008, pp. 154-155) menyatakankan ada tiga jenis kegiatan yang harus dipertimbangkan dengan cermat ketika melakukan kegiatan pelaksanaan kebijakan:

a) Interprestasi, menterjemahkan bahasa kebijakan ke dalam rencana dan arah yang dapat diterima;

b) Pengorganisasian, membuat atau mengatur kembali sumber dayasehingga kebijakan dapat memberikan hasil;

c) Penerapan, penyediaan layanan sesuai dengan tujuan atau program.

Lebih jelas diartikan interpretasi, organisasi dan penerapan/aplikasi diartikan sebagai berikut. Interpretasi adalah kegiatan yang bertujuan untuk menjelaskan makna dari suatu kebijakan secara lebihefektif dan bahasanya lebih mudah dimengerti, sehingga isi kebijakan dapat dilakukan dan diterapakan oleh aktor. Selanjutnya, organisasi adalah cara menentukan dan menyusun sumber daya, objek, dan langkah yang menuju pada keinginan untuk terwujudnya sesuatu maksud dan tujuan kebijakan. Terkahir, yaitu penerapan/aplikasi adalah kegiatan pemberian pelayanan secara berkala, baik pembayaran maupun lainnya sejalan dengan maksud serta tujuan peraturan yang ada.

Badan Ketahanan Pangan merumuskan kebijakan umum dengan tujuan untuk menjadikan swasembada guna menjamin tersedianya pangan yang berkualitas di dalam kalangan masyarakat secara seragam menggunakan sumber daya lokal berkualitas tinggi serta penguatan ekonomi yang berpihak kepada rakyat dalam mengatasi kemiskinan. (Purwaningsih, 2008).

Pemerintah menekankan kebijakan ketahanan pangan berpusat pada 
Vebi Hanifatun Saleha, Karjuni Dt. Ma'anil Implementasi Kebijakan Program Bedah Kemiskinan Rakyat Sejahtera (BEKERJA) dalam Menjamin Ketahanan Pangan Masyarakat di Nagari Lubuk Layang Kabupaten Pasaman

pemberdayaan masyarakat untuk membantu diri mereka sendiri dalam mengatasi permasalahan pangan yang ada saat ini. Pemberdayaan masyarakat ini terus dilakukan dengan meningkatkan daya tamping supaya mampu memproduksi, dan menjual produk, serta mampu memasuki pasar kerjadan memberikan peluang usaha untuk meningkatkan pendapatan. (Purwaningsih, 2008).

Program didefinisikan sebagai aplikasi dan sumber daya yang sistematis berdasarkan pemikiran yang mengidentifikasi hajat orang banyak. Program juga dapat dikatakan rangkaian kegiatan yang terencana, adanya sumber daya yang diolah, sasaran, kebutuhan yang jelas, teridentifikasi, serta keikutsertaan individu diimplementasikan dengan performance kerja yang bermanfaat.

Arikunto \& Jabar (2009:3) dalam (Munthe, 2015) ada beberapa penjelasan untuk istilah program, dijelaskan dalam makna umum dan khusus, merupakan suatu perencanaan yang dijalankan. Jika suatu kinerja berkaitan dengan evaluasi, dapat disimpulkan sebagai satuan kegiatan yang merupakan penerapan aturan, yang berlangsung dalam suatu organisasi.

Arikunto (Munthe, 2015) menyatakan program memiliki tiga makna penting yang harus ditekankan, yaitu (1) yang membuat aturan; (2) berjalan dalam kurung waktu yang lama, yang merupakan kegiatan jamak yang berkelanjutan; (3) dilaksanakan pada suatu organisasi yang melibatkan sekelompok orang. Program diartikan sebagai satuan tindakan yang dilaksanakan tidak hanya sekali tetapi terus menerus.

Program Pemerintah yang menjadi fokus kajian penelitian yaitu Program Kebijakan Bedah Kemiskinan Rakyat Sejahtera (Bekerja) dalam menjamin ketahanan pangan masyarakat di Kecamatan Rao Selatan Kabupaten Pasaman. Program BEKERJA berbasis pertanian merupakan untuk meningkatkan produksi hasil pertanian dalam rangka menaikkan penghasilan dan kesejahteraan dalam rangka pemberdayaan masyarakat tidak mampu.

\section{METODE PENELITIAN}

Metode penelitian yaitu kualitatif deskriptif yang dipakai untuk mendeskripsikan tentang hubungan antara kejadian dan hasilnya tidak dinyatakan dalam bentuk angka. Penelitian ini dilakukan untuk menggambarkan, mengidentifikasi kondisi selama penelitian dan berusaha mencari data yang berupa fakta-fakta secara utuh dan semaksimal mungkin. Hal ini sesuai dengan pendapat Bodgan \& Taylor, memaknai metode kualitatif ialah sebagai lanngkah maupun tahapan penelitian dan memperoleh data berbentuk deskriptif, berbentuk data perilaku yang diamati, kata lisan ataupun tertulis dari responden. (Basrowi \& Suwandi, 2008) Sedangkan teknik pengumpulan data memakai wawancara, observasi serta dokumentasi. Lokasi penelitiandi Nagari Lubuk Layang Kabupaten Pasaman. Uji keabsahan data menggunkan trianggulasi dan analisis penelitian menggunakan reduksi data, penyajian dan verifikasi data.

\section{HASIL DAN PEMBAHASAN}

Berdasarkan penelitian yang dilakukan penulis tentang implementasi kebijakan Program BEKERJA dalam Menjamin Ketahanan Pangan Masyarakat di Nagari Lubuk Layang Kabupaten Pasaman belum dapat berjalan sesuai dengan rencana, karena dapat dilihat dari teori Charles O. Jones dalam implementasinya masih ditemukan permasalahan dari indikator yang dialjabarkan:

\section{1) Interprestasi}

Interprstasi adalah upaya untuk memahami apa yang dimaksud pembuat kebijakan dan untuk mengetahui dengan tepat apa dan bagaimana tujuan akhir itu ingin dicapai atau dicapai. Dengan demikian, penafsiran penanggung jawab pelaksana kebijakan harus mengenal substansi kebijakan, pengertian kebijakan 
Vebi Hanifatun Saleha, Karjuni Dt. Ma'anil Implementasi Kebijakan Program Bedah Kemiskinan Rakyat Sejahtera (BEKERJA) dalam Menjamin Ketahanan Pangan Masyarakat di Nagari Lubuk Layang Kabupaten Pasaman

dan tujuan kebijakan agar tafsir tersebut tidak menyimpang dari kebijakan. (Permatasari, 2015).

Untuk mengetahui agar program Bedah Kemiskinan Rakyat Sejahtera (Bekerja) dalam menjamin ketahanan pangan masyarakat menjadi agar arah yang benar dapat dilaksanakan dengan baik, perlu diketahui siapa yang bertanggung jawab atas program tersebut, kemudian dalam pelaksanaannya jika sesuai dengan petunjuk pelaksanaan dan petunjuk teknis yang dikeluarkan oleh pejabat yang berwenang. Dimana pemerintah perlu menyusun strategi agar setiap kebijakan yang dikeluarkan publik bekerja secara aktif.

Sosialisasi ini bertujuan untuk memberikan informasi kepada masyarakat tentang program Bedah Kemiskinan Rakyat Sejahtera (Bekerja) dalam menjamin ketahanan pangan masyarakat. Namun Pelaksanaan sosialisasi yang dilakukan oleh pemerintah dengan masyarakat masih kurang karena masih ada masyarakat yang belum mengetahui program Bedah Kemiskinan Rakyat Sejahtera (Bekerja) dalam menjamin ketahanan pangan masyarakat di Kecamatan Rao Selatan Kabupaten Pasaman.

\section{2) Pengorganisasian}

Organisasi dalam rangka pelaksanaan kebijakan merupakan kegiatan yang bertujuan untuk membentuk lembaga, unit dan metode yang diperlukan untuk mencapai tujuan yang tertuang dalam kebijakan. Organisasi adalah satuan orang yang bekerja dalam kerangka administrasi.

Struktur organisasi pelaksanaan program Bedah Kemiskinan Rakyat Sejahtera (Bekerja) dalam menjamin ketahanan pangan masyarakat di Kecamatan Rao Selatan Kabupaten Pasaman terdiri dari Koordinator dari Dinas Pertanian, TKSK, Jorong dan juga tokoh masyarakat yang lainnya yang ikut berpartisipasi juga dalam melaksanakan program Bedah Kemiskinan Rakyat Sejahtera (Bekerja) ini, dan yang bertanggung jawab penuh dalam pelaksanaannya yaitu TKSK karena merupakan perpanjangan tangan dari Dinas Pertanian sendiri. Hal ini dilakukan guna melaksanakan dan menjalankan program Bedah Kemiskinan Rakyat Sejahtera (Bekerja) agar dapat mempermudah pelaksanaannya.

\section{3) Aplikasi/Penerapan}

Aplikasi adalah penerapan sistematis dari semua keputusan dan peraturan dalam melaksanakan kegiatan untuk mencapai tujuan kebijakan. Dalam hal ini, penerapan merupakan implementasi dari suatu hasil kerja yang diperoleh sedemikian rupa sehingga dapat di praktikkan di masyarakat. Hal ini harus dilakukan agar lebih mudah untuk menentukan apa yang harus dilakukan dan lebih mudah untuk mengimplementasikan program tersebut. Selain membahas prosedur, pemerintah juga mensosialisasikan pelaksanaan program ini yang merupakan prasyarat untuk kegiatan program.

Oleh karena itu, pemerintah terlebih dahulu melakukan kegiatan dengan memaparkan manfaatnya kepada masyarakat tentang program Bekerja dalam menjamin ketahanan pangan masyarakat, tujuannya agar program ini sesuai dengan kemauan, kapasitas dan keinginan masyarakat. Namun, kurangnya kesadaran masyarakat terhadap prosedur dan kebijakan yang ada menjadi salah satu penyebab sebagian besar tindakan disipliner dan manajemen waktu yang kurang optimal, yang mengakibatkan program kerja tidak berjalan dengan baik tidak diterapkan dalam jangka waktu yang telah ditentukan.

\section{PENUTUP}

Hasil penelitian dan pembahasan tentang Implementasi Kebijakan Program Bekerjadalam Menjamin Ketahanan Pangan Masyarakat di Nagari Lubuk Layang Kabupaten Pasaman belum terlaksana dengan baik. Bentuk sosialisasi yang dilakukan oleh pemerintah dengan 
Vebi Hanifatun Saleha, Karjuni Dt. Ma'anil Implementasi Kebijakan Program Bedah Kemiskinan Rakyat Sejahtera (BEKERJA) dalam Menjamin Ketahanan Pangan Masyarakat di Nagari Lubuk Layang Kabupaten Pasaman

masyarakat masih kurang karena ada sebagian masyarakat belum mengetahui program Bedah Kemiskinan Rakyat Sejahtera (Bekerja) dalam menjamin ketahanan pangan masyarakat di Nagari Lubuk Layang Kabupaten Pasaman. Pemerintah memberikan sosialisasi terhadap masyarakat tata cara melaksanakan program Bekerja tersebut. Namun, kurangnya kesadaran masyarakat terhadap prosedur dan kebijakan yang ada menjadi salah satu penyebab sebagian besar tindakan disipliner dan manajemen waktu yang kurang optimal, yang mengakibatkan program kerja tidak berjalan dengan baik.tidak diterapkan dalam jangka waktu yang telah ditentukan.

\section{DAFTAR KEPUSTAKAAN}

H., Akib, H., \& . H. (2016). Implementasi Kebijakan Program Makassar Tidak Rantasa (Mtr) Di Kota Makassar. Jurnal Ilmiah Ilmu Administrasi Publik.

https://doi.org/10.26858/jiap.v6i2.247 7

Aneta, A. (2012). Implementasi Kebijakan Program Penanggulangan Kemiskinan Perkotaan (P2KP) Di Kota Gorontalo. Jurnal Ilmiah Ilmu Administrasi Publik.

https://doi.org/10.26858/jiap.v1i1.132

Arenawati. (2014). Administrasi Pemerintah Daerah: Sejarah Konsep dan Pelaksanaan di Indonesia. Gava Media.

Basrowi \& Suwandi. (2008). Memahami Penelitian Kualitatif. Rineka Cipta.

Dwiyanto, I. (2009). Kebijakan Public Berbasis Dynamic Polici Analysis. Gava Media.

Leo, A. (2008). Dasar-Dasar Kebijakan Publik. Alfabeta.
Munthe, A. P. (2015). Pentingya Evaluasi Program Di Institusi Pendidikan: Sebuah Pengantar, Pengertian, Tujuan dan Manfaat. Scholaria: Jurnal Pendidikan Dan Kebudayaan. https://doi.org/10.24246/j.scholaria.20 15.v5.i2.p1-14

Pasolog, H. (2007). teori administrasi publik. Alfabeta.

Permatasari, K. (2015). Implementasi Kebijakan tentang Tata Kerja Pejabat Pengelola Informasi dan Dokumentasi di Kota Cimahi. Jurnal Bina Praja. https://doi.org/10.21787/jbp.07.2015.3 19-325

Purwaningsih, Y. (2008). Ketahanan Pangan: Situasi, Permasalahan, Kebijakan, Dan Pemberdayaan Masyarakat. Jurnal Ekonomi Pembangunan: Kajian Masalah Ekonomi Dan Pembangunan. https://doi.org/10.23917/jep.v9i1.1028

Rosyadi, I., \& Purnomo, D. (2012). Tingkat Ketahanan Pangan Rumah Tangga Di Desa Tertinggal. Jurnal Ekonomi Pembangunan: Kajian Masalah Ekonomi Dan Pembangunan. https://doi.org/10.23917/jep.v13i2.176

Wahab.S, A. (2013). Pengantar Analisis Implementassi Negara. Renika Cipta.

\section{Peraturan Perundang-undangan dan Pedoman Umum}

Media Auditor Edisi 48-September 2018 tentang Tata Kelola Bantuan Pemerintah Sektor Pertanian

Pedoman program bedah kemiskinan rakyat sejahtera, 2018.

Peraturan Menteri Pertanian Nomor 20/PERMENTAN/RC.120/5/2018 tentang Pedoman Program Bedah Kemiskinan Rakyat Sejahtera 
Vebi Hanifatun Saleha, Karjuni Dt. Ma'anil Implementasi Kebijakan Program Bedah Kemiskinan Rakyat Sejahtera (BEKERJA) dalam Menjamin Ketahanan Pangan Masyarakat di Nagari Lubuk Layang Kabupaten Pasaman

Berbasis Pertanian Tahun Anggaran 2018.

Undang-Undang Nomor 18 tahun 2012

Pasal 1 ayat 4 tentang Pangan. 